\title{
Translational and clinical perspectives on sphincter of Oddi dysfunction
}

\author{
Kondal Rao Kyanam \\ Kabir Baig',2 \\ Charles Melbern Wilcox' \\ 'Division of Gastroenterology and \\ Hepatology, University of Alabama, \\ ${ }^{2}$ Birmingham VA Medical Center, \\ Birmingham, AL, USA
}

This article was published in the following Dove Press journal:

Clinical and Experimental Gastroenterology

28 July 2016

Number of times this article has been viewed
Abstract: Sphincter of Oddi dysfunction is a complex pathophysiologic entity that is associated
with significant morbidity causing abdominal pain, nausea, and vomiting. The purpose of this review
is to describe the anatomy and physiology of the sphincter of Oddi, to understand the pathologic
mechanisms thought to be responsible for symptomatology, review recent major studies, explore
endoscopic and pharmacologic therapies and their efficacy, and to explore future research avenues. Keywords: SOD, abdominal pain, pancreatitis, sphincter dysfunction, abnormal liver tests, biliary dilation

\section{Overview \\ Historical perspective}

The sphincter of Oddi (SO) and its physiologic characteristics were first described by Ruggero Oddi in the late 1800 s. $^{1}$ The anatomy was further characterized in detail in the 1950s, including elucidation of the various muscle components and their function. ${ }^{2}$ The pathophysiology and dysfunction of this sphincter have undergone much iteration and has been the subject of multiple studies as well as debate.

\section{Definition and consensus criteria}

The ROME III criteria (Tables 1 and 2) defined biliary SO dysfunction (SOD) as epigastric or right upper quadrant pain which included all of the following: episodes of pain lasting at least 30 minutes, symptoms occurring at different intervals but not on a daily basis; the pain was constant in nature and was severe enough to alter or interrupt the patient's daily activities or lead to an emergency department visit; the pain was not relieved by postural changes, bowel movements, or antacid therapy; and finally, other structural pancreaticobiliary diseases were excluded. ${ }^{3}$

\section{Prior classification of SOD}

The Milwaukee classification was the first attempt to classify the SO and some of the criteria were obtained by invasive testing with endoscopic retrograde cholangiopancreatography (ERCP). ${ }^{4}$ The criteria were subsequently modified (Tables 3 and 4 ) in an attempt to avoid invasive testing and rely on clinical, biochemical, and conventional imaging findings. Rome IV criteria are the newest version and incorporate detailed clinical criteria along with objective imaging and biochemical parameters to classify SOD into three types based on the presence of objective radiologic and laboratory

\footnotetext{
Correspondence: Charles Melbern Wilcox

Division of Gastroenterology and Hepatology, University of Alabama, 1720 Second Ave South, BDB 380 Birmingham, Al 35294-0013, USA Email:melw@uab.edu
} 
Table I Diagnostic criteria by ROME IV (must include epigastric or right upper quadrant pain)

I. Episodes lasting 30 minutes or longer.

2. Recurrent symptoms occurring at different intervals (not daily).

3. The pain builds up to a steady level.

4. The pain is moderate to severe enough to interrupt the patient's daily activities or lead to an emergency department visit.

5. The pain is not relieved by bowel movements.

6. The pain is not relieved by postural change.

7. The pain is not relieved by antacids.

8. Exclusion of other structural diseases that would explain the symptoms.

Note: Data from Cotton et al. ${ }^{3}$

Table 2 Supportive criteria for ROME IV criteria

The pain may present with one or all of the following:

I. associated with pain or vomiting;

2. radiates to the back and/or right infrasubscapular region;

3. awakens from sleep in the middle of the night.

Note: Data from Cotton et al. ${ }^{3}$

Table 3 Classification of biliary SOD

\begin{tabular}{ll}
\hline SOD type & Diagnostic criteria \\
\hline Type I & $\begin{array}{l}\text { Pain and abnormal hepatic enzymes } \\
\text { dilated bile duct }\end{array}$ \\
Type 2 & $\begin{array}{l}\text { Pain and abnormal hepatic enzymes } \\
\text { dilated bile duct }\end{array}$ \\
Type 3 & Pain with normal hepatic enzymes and normal bile duct
\end{tabular}

Note: ${ }^{\text {aT }}$ wice the upper limit of normal.

Abbreviation: SOD, sphincter of Oddi dysfunction.

Table 4 Classification of pancreatic SOD

\begin{tabular}{ll}
\hline SOD type & Diagnostic criteria \\
\hline Type I & $\begin{array}{l}\text { Pain and abnormal pancreatic enzymes } \\
\text { and dilated pancreatic duct }\end{array}$ \\
Type 2 & $\begin{array}{l}\text { Pain and abnormal pancreatic enzymes on on two occasions } \\
\text { or dilated pancreatic duct }\end{array}$ \\
Type 3 & $\begin{array}{l}\text { Pain with normal pancreatic enzymes and normal } \\
\text { pancreatic duct }\end{array}$ \\
\hline
\end{tabular}

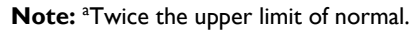

Abbreviation: SOD, sphincter of Oddi dysfunction.

criteria. ${ }^{5,6}$ The previously used invasive manometry criteria are no longer utilized. ${ }^{5}$

\section{Anatomy of SOD}

The SO consists of circular muscles that are oriented circumferentially and also in a figure-of-eight configuration around the biliary and pancreatic orifice. The contractile component measures $5-10 \mathrm{~mm}$ and is responsible for the contractile activity of the sphincter. The biliary and pancreatic sphincters are anatomically distinct and are described as such, though there is overlap. The complex of four sphincters surround the intramural part of the common bile duct and pancreatic ducts, and these are the sphincter of the ampulla, superior sphincter choledochus, inferior sphincter choledochus, and sphincter pancreaticus., ${ }^{2,7}$

\section{Physiology}

The human SO is similar in structure and function to carnivorous species such as cats and dogs. ${ }^{8,9}$ The primary regulatory mechanism is that of resisting bile flow from simultaneous contractions of the SO musculature regulated through the release of cholecystokinin and secretin. ${ }^{10}$ Release of this neuropeptide in response to a fatty meal causes the contraction of the gallbladder and simultaneous relaxation of the $\mathrm{SO}$ and the duodenum leading to the passage of bile into the duodenum. ${ }^{11}$ The human SO has sustained basal pressures ranging from 5 to $15 \mathrm{~mm} \mathrm{Hg}$ with occasional phasic contractions as high as $150 \mathrm{~mm} \mathrm{Hg}$. The basal pressures are higher than the duodenal pressures preventing reflux of duodenal contents into the bile duct. ${ }^{12}$ It is not clear if the phasic contractions are intended to prevent duodenal biliary reflux or to keep bile within the gallbladder in a fasting state, and both of these roles have been postulated in trying to understand the phasic contractions. ${ }^{13}$ The contractions are closely related to the migrating motor complex. The fasting and digestive states and the nature of the food ingested regulate the SO basal and phasic pressures and its function through neurohormonal mechanisms mediated by cholinergic and adrenergic pathways. ${ }^{9}$ The effect of these pathways is inhibitory and is thought to be mediated through vasoactive intestinal peptide. ${ }^{14}$

\section{Treatment of SOD Pharmacologic therapy}

Multiple pharmacologic agents have been evaluated for the treatment of SOD. However, there are no randomized controlled trials that have revealed a true therapeutic benefit. Medications that have been evaluated include nitrates, ${ }^{15,16}$ calcium channel blockers, ${ }^{17,18}$ and ursodeoxycholic acid. ${ }^{19}$

Among the calcium channel blockers, nifedipine has been the most commonly studied agent. Khuroo et al conducted a randomized, double blind crossover study of 28 SOD patients. ${ }^{17}$ The highest tolerated dose was compared to placebo. There was a significant decrease in analgesic use, pain score, pain episodes, and hospital visits. The trial did not reveal any clinical, radiologic, or manometric predictors of response. ${ }^{17}$ In a small placebo-controlled crossover trial involving five patients by Craig and Toouli, nifedipine was no more effective than placebo and often caused vascular side effects. ${ }^{18}$

Nitrates are known to cause smooth muscle relaxation. However, these agents have not been studied specifically for 
the treatment of SOD. An experimental study revealed that nitrates may cause SO relaxation in patients with abdominal pain that is not necessarily due to SOD. ${ }^{16} \mathrm{~A}$ case report suggested sustained response to nitrate therapy in an elderly female with known SOD. ${ }^{15}$

Microlithiasis has long been thought to be the cause of pain in type 1 SOD patients, particularly postcholecystectomy patients. In a study by Okoro et al, 12 patients with microlithiasis were selected out of 118 patients with postcholecystectomy pain. ${ }^{19}$ These patients were treated with ursodeoxycholic acid for 6 months in a randomized, double blind, crossover fashion and there was significant improvement in pain in the treatment arm. Most patients (11/12) remained pain free at 29 months. ${ }^{19}$ However, the study was small and not generalizable, and larger randomized studies are needed to confirm the results. ${ }^{20}$

\section{Endoscopic therapy}

There have been three randomized controlled trials evaluating endoscopic sphincterotomy as a therapy for SOD.

The seminal study by Geenen et al randomized 47 patients (Table 5) with postcholecystectomy abdominal pain, who met criteria for SOD type 2 , to biliary sphincterotomy and sham sphincterotomy. ${ }^{21}$ Manometry was performed but was not utilized to direct sphincterotomy. In the patients who had elevated SO pressures, 10/11 patients had improved pain scores at the end of 1 year. However, in patients with elevated sphincter pressures who were in the sham arm, only $3 / 12$ patients showed improvement in pain scores. In patients with normal SO pressures, sphincterotomy made no difference. A strength of this study is that 40 patients were followed for over 4 years and overall 17/18 patients with elevated pressures showed improved pain scores. ${ }^{21}$

Toouli et al performed a randomized controlled trial following a different algorithm. Eighty-one patients with SOD type 2 underwent biliary manometry and were classified as having papillary stenosis, biliary dyskinesia or normal, based on an elevated basal pressure of $>40 \mathrm{~mm} \mathrm{Hg} .{ }^{22}$ Based on the SO manometry, each group of patients were randomized to sphincterotomy or sham. In those with SO hypertension, $85 \%$ of patients who underwent sphincterotomy showed

Table 5 Randomization of SO pressure

\begin{tabular}{lll}
\hline SO pressure & $\begin{array}{l}\text { Biliary } \\
\text { sphincterotomy }\end{array}$ & $\begin{array}{l}\text { Sham } \\
\text { sphincterotomy }\end{array}$ \\
\hline Elevated SO pressure & $11^{\mathrm{a}}$ & $12^{\mathrm{b}}$ \\
Normal SO pressure & 12 & 12 \\
\hline
\end{tabular}

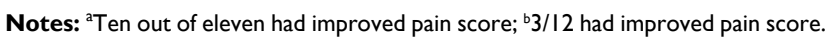
Data from Geenan et al. ${ }^{21}$

Abbreviation: SO, sphincter of Oddi. improvement in pain scores vs $38 \%$ of those who underwent the sham procedure. In the biliary dyskinesia group, $36 \%$ in the treatment group had symptomatic improvement compared to $50 \%$ in the control group. In the normal SO pressure group, $61 \%$ in the treatment group had symptomatic improvement compared to $42 \%$ in the control group. The high rate of response in the sham group is notable. The overall rate of SOD type 2 in this group was relatively low at $\sim 30 \% .^{22}$

The most recent study, the EPISOD trial is the largest and most comprehensive. ${ }^{23}$ The results have definitively established the lack of efficacy of biliary sphincterotomy as a treatment form for SOD type 3. This was a comprehensive trial that was well designed and attempted to address all the issues encompassing SOD type 3 and its treatment with sphincterotomy. Patients in seven different centers were evaluated. Inclusion criteria were age $18-65$ years; postcholecystectomy pain for $>3$ months; no history of pancreatitis or laboratory and imaging parameters suggestive of pancreatitis; and no prior sphincterotomy. The exclusion criteria were robust and a careful effort was made to exclude subjects with SOD type 2, and significant narcotic use or known psychological morbidity (Table 6). Multiple validated questionnaires were administered to determine psychological characteristics and the overall burden of pain.

After fulfilling the initial criteria, patients were selected based on lack of response to acid-suppressing agents and antispasmodics, presence of unremarkable upper endoscopy and abdominal imaging showing a bile duct $\leq 9 \mathrm{~mm}$, and on a stable dose of antidepressants.

A total of 214 patients underwent SO manometry and were randomized to biliary sphincterotomy or sham in a 2:1 ratio. Those undergoing sphincterotomy were further randomized to biliary sphincterotomy or dual (biliary and pancreatic) sphincterotomy. The main outcome measure was reduction of pain score as measured by the recurrent abdominal pain intensity and disability instrument at 9 and 12 months.

The results of this trial were dramatic and revealed that endoscopic sphincterotomy offered no benefit over sham.

Table 6 Exclusion criteria for the EPISOD study

Direct bilirubin, alkaline phosphatase, amylase or lipase $>$ twice normal Transaminases $>$ thrice normal

Narcotic analgesic use every day in the past month

Known pancreas divisum

Abnormal endoscopic ultrasound (if done)

Prior surgical biliary diversion

Significant medical problems

Significant psychiatric problems

Pregnancy

Note: Data from Cotton et al..$^{23}$ 
In fact, the pain scores were better in the sham group. The results of this trial effectively call into question the existence of SOD type 3 as reflected in the Rome IV classification. The rate of post-ERCP pancreatitis among this group of patients who underwent ERCP in expert hands was $12 \%$ underscoring the risk of ERCP in SOD type 3 patients. This was despite the uniform use of prophylactic pancreatic stents. Rectal indomethacin was not used in these patients.

Botulinum injection in the treatment of biliary and SOD type pain of the ampulla has been studied with equivocal results. The mechanism of action is presumed to be the paralytic relaxation of the ampullary smooth muscle and sphincters. Wehrmann et al found that botulinum injection may provide temporary relief of symptoms and may predict success of biliary sphincterotomy in SOD patients. ${ }^{24}$ In a more recent study, Murray and Kong were able to reproduce these results in a subset of patients with biliary pain. They found that $72 \%$ of patients who underwent injection had relief from pain up to 4 weeks, and $96 \%$ of these patients had a successful response to biliary sphincterotomy. ${ }^{25,26}$ The study was observational and not randomized. The significant placebo effect of endoscopic interventions on outcomes related to pain calls into question the effectiveness of the therapy and generalizability of the results. ${ }^{27,28}$

\section{Current state of knowledge}

While the EPISOD trial effectively addresses the lack of benefit of sphincterotomy in SOD type 3 patients, questions remain regarding SOD types 1 and 2. Most type 1 patients are thought to have papillary stenosis and symptoms related to sludge and small stone passage. ${ }^{29}$ Retrospective studies in this group of patients have shown promising results but controlled trials have been lacking. ${ }^{30-33}$ The EPISOD trial suggests the lack of benefit in a small group of patients within their trial who overlapped as SOD type $2 .{ }^{23}$ Large-scale randomized controlled trials are necessary to evaluate the benefit of sphincterotomy in SOD types 1 and 2 .

Evaluation of pharmacotherapeutic agents in the treatment of SOD gains more relevance in the context of the EPISOD trial. Candidate medications include nonspecific smooth muscle dilators such as calcium channel blockers and nitrates. Other novel targeted therapeutic agents may also be developed with a better understanding of the SO function and its regulation through the gastrointestinal neuro-hormonal pathway.

\section{Future considerations}

There is still much to learn regarding the SO, both its function and dysfunction. One of the major limitations has been the inability to monitor the sphincter over a prolonged period of time like one can do for heart arrhythmias and esophageal acid exposure. The development of new technology to provide such monitoring would be a significant advancement. In addition, we need to learn more regarding the neurohormonal aspects of sphincter physiology. It is possible that in some way the sphincter is sensitized and this might explain the reported response to botulinum toxin. Whether injection of botulinum toxin would provide long-term benefit will require randomized controlled trials, particularly since any manipulation of the sphincter can result in acute pancreatitis.

The utility of contrast enhanced magnetic resonance imaging using secretin for the noninvasive diagnosis of SOD has been evaluated in the past with equivocal results. ${ }^{34}$ Newer technology with higher resolution imaging using enhanced and novel contrast agents might change this paradigm in evaluating the pancreaticobiliary tract and its pathology, including SOD. ${ }^{35}$

With rapid advancements in genetics, there could be a genetic component to not only sphincter dysfunction but also the genesis of pain itself. A recent abstract suggested that among SOD type 3 patients, there is a higher prevalence of genes associated with chronic pancreatitis and in a limited number of patients, the presence of these genes predicted a poor response to endoscopic therapy. ${ }^{36}$ As with any disease, genegene interactions could be causative. Lastly, the development of smooth muscle relaxers specific for the sphincter would be a welcome addition, but would also require major advances in pharmacology to provide such directed smooth muscle control.

\section{Disclosure}

The authors report no conflicts of interest in this work.

\section{References}

1. Capodicasa E. Ruggero Oddi: 120 years after the description of the eponymous sphincter: a story to be remembered. $J$ Gastroenterol Hepatol. 2008;23(8 Pt 1):1200-1203.

2. Boyden EA. The anatomy of the choledochoduodenal junction in man. Surg Gynecol Obstet. 1957;104(6):641-652.

3. Cotton PB, Elta GH, Carter CR, Pasricha PJ, Corazziari ES. Gallbladder and Sphincter of Oddi Disorders. Gastroenterology. 2016;150:1420-1429.

4. Geenen JE, Hogan WJ, Dodds WJ, Stewart ET, Arndorfer RC. Intraluminal pressure recording from the human sphincter of Oddi. Gastroenterology. 1980;78(2):317-324.

5. Hogan WJ, Geenen JE, Dodds WJ. Dysmotility disturbances of the biliary tract: classification, diagnosis, and treatment. Semin Liver Dis. 1987;7(4):302-310.

6. Wilcox CM. Sphincter of Oddi dysfunction Type III: new studies suggest new approaches are needed. World J Gastroenterol. 2015;21(19):5755-5761.

7. Seetharam P, Rodrigues G. Sphincter of Oddi and its dysfunction. Saudi J Gastroenterol. 2008;14(1):1-6.

8. Behar J. Physiology and pathophysiology of the biliary tract: the gallbladder and sphincter of Oddi-a review. ISRN Physiology. 2013;2013:837630. 
9. Behar J, Biancani P. Effect of cholecystokinin and the octapeptide of cholecystokinin on the feline sphincter of Oddi and gallbladder. Mechanisms of action. J Clin Invest. 1980;66(6):1231-1239.

10. Hanyu N, Dodds WJ, Layman RD, Hogan WJ. Cholecystokinin-induced contraction of opossum sphincter of Oddi. Mechanism of action. Dig Dis Sci. 1990;35(5):567-576.

11. Toouli J. Sphincter of Oddi: function, dysfunction, and its management. J Gastroenterol Hepatol. 2009;24 Suppl 3:S57-S62.

12. Geenen J, Hogan W, Stewart E, et al. ERCP manometry of the sphincter of Oddi. In: Classen M, Geenen JE, Kawai K, editors. The Papilla Vater and Its Diseases. Köln, Germany: Witzstrock; 1979:92-98.

13. Sherman S, Lehman GA. Sphincter of Oddi dysfunction: diagnosis and treatment. JOP. 2001;2(6):382-400

14. Becker JM. Physiology of motor function of the sphincter of Oddi. Surg Clin North Am. 1993;73(6):1291-309.

15. Bar-Meir S, Halpern Z, Bardan E. Nitrate therapy in a patient with papillary dysfunction. Am J Gastroenterol. 1983;78(2):94-95.

16. Brandstatter $\mathrm{G}$, Schinzel $\mathrm{S}$, Wurzer H. Influence of spasmolytic analgesics on motility of sphincter of Oddi. Dig Dis Sci. 1996;41(9):1814-1818.

17. Khuroo MS, Zargar SA, Yattoo GN. Efficacy of nifedipine therapy in patients with sphincter of Oddi dysfunction: a prospective, double-blind, randomized, placebo-controlled, cross over trial. Br J Clin Pharmacol. 1992;33(5):477-485

18. Craig AG, Toouli J. Slow release nifedipine for patients with sphincter of Oddi dyskinesia: results of a pilot study. Intern MedJ. 2002;32(3):119-120.

19. Okoro N, Patel A, Goldstein M, Narahari N, Cai Q. Ursodeoxycholic acid treatment for patients with postcholecystectomy pain and bile microlithiasis. Gastrointest Endosc. 2008;68(1):69-74.

20. Ahmed F, Sherman S. Should patients with biliary-type pain after cholecystectomy be evaluated for microlithiasis? Gastrointest Endosc. 2008;68(1):75-77.

21. Geenen JE, Hogan WJ, Dodds WJ, Toouli J, Venu RP. The efficacy of endoscopic sphincterotomy after cholecystectomy in patients with sphincter-of-Oddi dysfunction. N Engl J Med. 1989;320(2):82-87.

22. Toouli J, Roberts-Thomson IC, Kellow J, et al. Manometry based randomised trial of endoscopic sphincterotomy for sphincter of Oddi dysfunction. Gut. 2000;46(1):98-102.

23. Cotton PB, Durkalski V, Romagnuolo J, et al. Effect of endoscopic sphincterotomy for suspected sphincter of Oddi dysfunction on painrelated disability following cholecystectomy: the EPISOD randomized clinical trial. JAMA. 2014;311(20):2101-2109.
24. Wehrmann T, Seifert H, Seipp M, Lembcke B, Caspary WF. Endoscopic injection of botulinum toxin for biliary sphincter of Oddi dysfunction. Endoscopy. 1998;30(8):702-707.

25. Murray W, Kong S. Botulinum toxin may predict the outcome of endoscopic sphincterotomy in episodic functional post-cholecystectomy biliary pain. Scand J Gastroenterol. 2010;45(5): 623-627.

26. Murray WR. Botulinum toxin-induced relaxation of the sphincter of Oddi may select patients with acalculous biliary pain who will benefit from cholecystectomy. Surg Endosc. 2011;25(3): 813-816.

27. Moore RA, Derry S, Wiffen PJ. Challenges in design and interpretation of chronic pain trials. Br J Anaesth. 2013;111(1):38-45.

28. Schulz KF, Grimes DA. Blinding in randomised trials: hiding who got what. Lancet. 2002;359(9307):696-700.

29. Rashdan A, Fogel E, McHenry L Jr, Lehman G, Sherman S. Frequency of biliary crystals in patients with suspected sphincter of Oddi dysfunction. Gastrointest Endosc. 2003;58(6):875-878.

30. Heetun ZS, Zeb F, Cullen G, Courtney G, Aftab AR. Biliary sphincter of Oddi dysfunction: response rates after ERCP and sphincterotomy in a 5-year ERCP series and proposal for new practical guidelines. Eur J Gastroenterol Hepatol. 2011;23(4):327-333.

31. Wehrmann T. Long-term results ( $\geq 10$ years) of endoscopic therapy for sphincter of Oddi dysfunction in patients with acute recurrent pancreatitis. Endoscopy. 2011;43(3):202-207.

32. Wehrmann T, Wiemer K, Lembcke B, Caspary WF, Jung M. Do patients with sphincter of Oddi dysfunction benefit from endoscopic sphincterotomy? A 5-year prospective trial. Eur J Gastroenterol Hepatol. 1996;8(3):251-256.

33. Hogan WJ, Sherman S, Pasricha P, Carr-Locke D. Sphincter of Oddi manometry. Gastrointest Endosc. 1997;45(3):342-348.

34. Pereira SP, Gillams A, Sgouros SN, Webster GJ, Hatfield AR. Prospective comparison of secretin-stimulated magnetic resonance cholangiopancreatography with manometry in the diagnosis of sphincter of Oddi dysfunction types II and III. Gut. 2007;56(6): 809-813.

35. Lee NK, Kim S, Lee JW, et al. Biliary MR imaging with Gd-EOB-DTPA and its clinical applications. Radiographics. 2009;29(6):1707-1724.

36. Ridtitid W, Cote G, Ballard D, et al. Sphincter of Oddi dysfunction type 3: genetic testing for pancreas-specific mutations. Gastroenterology. $2015 ; 148:$ S-340.
Clinical and Experimental Gastroenterology

\section{Publish your work in this journal}

Clinical and Experimental Gastroenterology is an international, peerreviewed, open access, online journal publishing original research, reports, editorials, reviews and commentaries on all aspects of gastroenterology in the clinic and laboratory. This journal is included on PubMed. The manuscript management system is completely online

\section{Dovepress}

and includes a very quick and fair peer-review system, which is all easy to use. Visit http://www.dovepress.com/testimonials.php to read real quotes from published authors. 